\title{
Muscle Dysmorphia Among Current and Former Steroid Users
}

\author{
Rebecca Davies and Dave Smith \\ Manchester Metropolitan University, UK \\ Kevan Collier \\ Scientiam Ltd., UK
}

\begin{abstract}
This study examined the presence and experience of muscle dysmorphia among current and former steroid-using recreational bodybuilders. The Muscle Dysmorphia Inventory was given to 60 male participants, with 9 of these being interviewed to examine the predisposing factors, characteristics, and negative consequences of muscle dysmorphia comprising Lantz, Rhea, and Mayhew's (2001) conceptual model. Quantitative results from the MDI data showed no significant differences between current and former steroid users in their experiences of muscle dysmorphia. In contrast, interviews suggested that former users appeared to be more susceptible to some of the characteristics of muscle dysmorphia, including physique protection and body distortion/dissatisfaction, which suggests perhaps a limitation in the amount of information that can be extracted from a questionnaire. These preliminary findings also raise concerns about the lack of a diagnostic tool available for the condition and are discussed in relation to Lantz et al.'s (2001) conceptual model.
\end{abstract}

Keywords: steroids, muscle dysmorphia, bodybuilders, sport

The use of anabolic/androgenic steroids (AAS) as an aid to competitive bodybuilding is common in the United Kingdom (Grogan, Shepherd, Evans, Wright, \& Hunter, 2006; Lenehan, Bellis, \& McVeigh, 1996; Wright, Grogan, \& Hunter, 2000), with much research suggesting that this is also prevalent among recreational gym users (Smith, Hale, Rhea, Olrich, \& Collier, 2009). Furthermore, research conducted in the United Kingdom and United States has suggested the motives for this group's AAS use includes increasing muscle mass and strength and increasing physical attractiveness (Cohen, Collins, Darkes, \& Gwartney, 2007; Smith et al., 2009).

The physical appearance motive for AAS use appears to be a consistent and powerful one and has been reported extensively in the literature (Smith et al., 2009; Wright et al., 2000). The recently-documented condition of muscle dysmorphia lends support to this suggestion. Muscle dysmorphia, first named as such by Pope,

Rebecca Davies and Dave Smith are with the Exercise \& Sport Science Department at Manchester Metropolitan University in the UK. Kevan Collier is with Scientiam Ltd., UK. 
Gruber, Choi, Olivardia, and Phillips (1997), is a form of body dysmorphic disorder in which sufferers become pathologically preoccupied with their degree of muscularity. They perceive their bodies as small and weak, despite actually being large and muscular. The disorder tends to result in an all consuming lifestyle involving training and diet, impaired social and occupational functioning, and severe distress if their bodies are seen in public (Pope et al., 1997). Cafri et al. (2005) suggested that this often culminates in the use of steroids to try to improve muscularity. Indeed, Olivardia, Pope, and Hudson (2000) reported that muscle dysmorphia preceded steroid use in $73 \%$ of their sample.

Lantz, Rhea, and Mayhew (2001) developed a conceptual model of muscle dysmorphia. They identified two precipitating factors, self-esteem and body dissatisfaction, that increase motivation to engage in exercises aimed at physique development. The development of muscles may then increase self-esteem, which will increase commitment to the exercise regimen; this in turn is problematic if a person's self-esteem becomes dependent on this connection.

The six behavioral characteristics that develop from muscle dysmorphia, according to the model, include body size/symmetry (e.g., concern with developing the "ideal" male body that is muscular and symmetrical), dietary constraints (e.g., diet centered around gaining muscle), physique protection (e.g., hiding in baggy clothes), supplement use (e.g., energy drinks), pharmacological abuse (e.g., AAS and synthetic hormones), and exercise dependence (i.e., compulsive exercise). Each characteristic could then maintain a cyclical influence of more pathological behaviors. For example, as a person's attitude toward his or her body becomes more pathological, he or she may begin to change diet to develop the physique. As his or her physique develops, he or she will associate this with the change in diet, and so that behavior is increasingly reinforced. Lantz et al. suggested that this reinforcement would strengthen the individual's view of the connection between the precipitating factors (self-esteem and body dissatisfaction) and the pathological attitudes surrounding his or her physical development.

There are three negative consequences thought to develop from these pathological attitudes, according to Lantz et al. (2001). These are alienation from everything not associated with training, narcissism or a preoccupation with oneself, and positive deviance or over-conformity to bodybuilding role, possibly resulting in training while ill or injured.

Lantz, Rhea, and Cornelius (2002) used the 27-item Muscle Dysmorphia Inventory (MDI; Rhea, Lantz, \& Cornelius, 2004) to examine elements of Lantz et al.'s (2001) conceptual model in elite bodybuilders and power lifters. They concluded that bodybuilders were more likely to display muscle dysmorphia characteristics than were power lifters; however, it is important to note that the MDI only measures the behavioral characteristics and not the predisposing factors or negative consequences of muscle dysmorphia.

While motives for AAS use have been documented among current users, research investigating cessation motives has been limited. Some researchers have suggested that cessation motives are related to other sources of self-esteem entering users' lives, such as marriage and children (Olrich \& Ewing, 1999; Olrich \& Vassallo, 2006). Former AAS users' motivations to quit seem to derive from having other sources of self-esteem rather than just their physiques. In contrast, a study using the modified Eating Disorders Inventory (EDI) reported that characteristics 
of muscle dysmorphia persisted in some former users, with their scores being significantly higher than current users (Cole, Smith, Halford, \& Wagstaff, 2003); however, the latter study had a small sample (19) and used a measure that had not been validated. Therefore, further research is needed to increase our understanding of the psychological issues and difficulties surrounding cessation, to enable appropriate coping and support methods to be created.

\section{Present Study}

The aim of the current study was to compare the prevalence of muscle dysmorphia in current and former steroid users, using the Muscle Dysmorphia Inventory (MDI; Rhea et al., 2004). A series of qualitative interviews were conducted to elucidate specific elements of the model and explore the experiences of muscle dysmorphia among the two groups in relation to this model. The reason for the use of both questionnaires and interviews in this study was because the MDI does not capture all elements of Lantz et al.'s (2001) model, namely the predisposing and negative consequence factors. Similarly, a mixed-methods approach would enable a quantitative sample (questionnaire respondents) to be used to identify a smaller group (interviewees) for more in depth study. This decision was based on the work of Brannen (2005) who identified this as a major advantage of mixed-methods research. The use of interviews was also to provide a better understanding of the people behind the quantitative data, a point reinforced by Harden and Thomas (2005) and Silverman (2004). We sought to further explore the relationship between steroid use and muscle dysmorphia. Based on suggestions from previous research, we expected muscle dysmorphia characteristics to perhaps be more prevalent in current steroid users, with a decline in former users (Cafri et al., 2005; Lantz, Rhea, \& Mayhew, 2001). As previous research has been limited and contradictory (Cole, Smith, Halford, \& Wagstaff, 2003), however, we made no firm predictions, as we believed this could potentially lead to an interpretation bias in the qualitative portion of this research.

\section{Method}

\section{Participants}

Following approval for the project by the University's ethics committee, a total of 60 male participants were recruited for the questionnaire part of the study, 30 being current AAS users and 30 being former users. The participants were all members of bodybuilding gymnasia and classed themselves as noncompetitive bodybuilders. The average age of the participants was 30, with current users ranging from 18 to 70 years and former users ranging from 18 to 48 years.

The participants were recruited in several ways. First, a number of them were contacts of the first author and others participated as a result of a snowball sample, whereby existing participants recruited their acquaintances. Second, two bodybuilding gyms in the northwestern region of England agreed to place a number of questionnaires on their reception desks. Finally, online steroid and bodybuilding forums (www.t-nation.com, www.uk-muscle.co.uk, www.uk-muscle.com, www. ironmagazine.com) were used to recruit participants. A participant information sheet, describing the main aims of the study as well as confidentiality issues, was given to each gym and was included in the forum posts. 
The interviews were conducted with four former and five current AAS users who were among the 60 overall participants. These nine participants indicated on a separate form included in the questionnaire packet that they would consent to participating in an interview. Five of the interviewees were recruited from online forums, while the other four were recruited from the gyms mentioned above.

\section{Instrumentation}

The questionnaire packet was comprised of two parts. The first part consisted of 21 background questions including demographics, gym use, AAS use, and supplement use. These questions were included to enable the pattern of AAS, frequency of weight training, and other related issues to be examined in more detail. Questions were included regarding the cycling of AAS and "stacking" (i.e., the consumption of more than one type of AAS simultaneously).

The second part of the questionnaire consisted of the Muscle Dysmorphia Inventory (MDI; Rhea et al., 2004). The MDI is a 27-item, self-report measure designed to assess the behavioral and psychological characteristics of muscle dysmorphia. The MDI consists of six subscales based on the conceptual model of muscle dysmorphia (Lantz et al., 2001). The subscales are body size/symmetry (e.g., "I will benefit from having large muscles"), physique protection (e.g., "I prefer to work out when no one else can see me"), exercise dependence (e.g., "It bothers me to miss a scheduled workout"), supplement use (e.g., "I use nutritional supplements to help me train through injury"), dietary behavior (e.g., "I regulate my caloric intake to maximize muscle development"), and pharmacological use (e.g., "I use steroids/laxatives"). Each item is scored on a 6-point Likert scale ranging from 1 (never) to 6 (always). All subscales have shown an acceptable level of internal reliability as per Rhea et al. (Chronbach's alpha $=0.72-0.94)$. Rhea et al. (2004) also documented significant correlations between the MDI subscales and the drive for thinness subscale of the Eating Disorders Inventory (Garner, Olmstead, \& Polivy, 1983), and the training dependence subscale of the Bodybuilding Dependence Scale (Smith, Hale, \& Collins, 1998), providing evidence of convergent validity.

\section{Procedure}

The questionnaires were either given in person to participants or were sent out via e-mail. Written informed consent was obtained from all participants before participation. The interview phase of the study was conducted after the questionnaires were collected. The participants who did consent to being interviewed were contacted by e-mail and were given more details about the interview. Four former and five current AAS users agreed to be interviewed. All interviews were recorded and subsequently transcribed.

The interviews were semistructured, consisting of open-ended questions. The questions covered elements of Lantz et al.'s (2001) conceptual model of muscle dysmorphia and investigated further the items covered on the MDI. There were also some introductory questions to make the participants feel at ease before discussing their steroid use. The topics within the interview plan and example subtopics for the current steroid users can be seen in Table 1. The interview plan was slightly different for former users, such as asking whether they felt or behaved differently after cessation rather than just while using or before taking steroids. The interviews lasted between 30 and $45 \mathrm{~min}$. 


\section{Table 1 Interview Plan for Current and Former AAS Users}

\begin{tabular}{|c|c|}
\hline Interview Topic & Subtopics/Questions \\
\hline Introduction & $\begin{array}{l}\text { Training: when/how started AAS use; when/how } \\
\text { introduced }\end{array}$ \\
\hline Self-esteem & Different before, during, after AAS \\
\hline Body dissatisfaction/distortion & Happy with body before, during, after AAS \\
\hline Body size/symmetry & $\begin{array}{l}\text { Happy with your size/symmetry; comparisons } \\
\text { with others }\end{array}$ \\
\hline Dietary constraints & Specific diet; cheat days \\
\hline Pharmacological aids \& supplements & $\begin{array}{l}\text { Types of supplements and why AAS use and } \\
\text { side effects }\end{array}$ \\
\hline Exercise dependence & Training regimen; feelings on missing a session \\
\hline Physique protection & Avoiding situations; covering with clothes \\
\hline Negative consequences & $\begin{array}{l}\text { Alienation due to training; time spent training; } \\
\text { training if ill/injured }\end{array}$ \\
\hline
\end{tabular}

\section{Data Analysis}

To determine if muscle dysmorphia characteristic differences existed between former and current AAS users, a $2 \times 6$ (group $\times$ MDI subscale) MANOVA was conducted on the questionnaire data. The interview data were color coded according to the elements of Lantz et al.'s (2001) conceptual model of muscle dysmorphia. The data were then subjected to a more detailed analysis in which topics within the above categories were identified. This enabled patterns to be identified while preserving the narrative account of the participants. This method was a version of a "thematic analysis," based on the methods of Miles and Huberman (1994). To enable the interrater reliability of the data analysis to be established, two of the authors analyzed the data separately and the themes that emerged from these two separate analyses were checked for consistency, as per Armstrong, Gosling, Weinman, and Marteau (1997). The interview themes identified were consistent between the first and third authors' separate analyses of the data, in that $95 \%$ were the same themes in both authors' analyses. These were largely related to the model by Lantz et al. (2001). The remaining themes identified by both authors were all subthemes of the main components of the model and were included as part of the main themes. Finally the interview data were compared with the quantitative MDI scale data to identify any relevant similarities or differences in the accounts of those interviewed.

\section{Results}

\section{Muscle Dysmorphia Inventory}

A $2 \times 6$ MANOVA revealed no significant multivariate effect, i.e., no difference between former and current AAS users in terms of their experience of muscle dysmorphia characteristics overall: $F(1,58)=1.34, p=0.26$ (ns). While the differences between the groups were not significant, the mean scores on five subscales of the MDI were higher for former steroid users. These differences were more pronounced for the subscales of body size/symmetry (current users: 20.5/30; 
former users: 21.7/30), and exercise dependence (current users: 17.8/24, former users: 19.2/24). The nonsignificance of these findings, however, suggests that this may be due to chance. In addition, the MDI does not account for all elements of Lantz et al.'s (2001) conceptual model, as it does not address the predisposing or negative consequence factors of muscle dysmorphia. The interview data will be reviewed to add to the findings of the MDI and will be discussed in relation to the aforementioned muscle dysmorphia model.

\section{Former Users}

Predisposing Factors: Self-Esteem and Body Distortion/Dissatisfaction. Selfesteem is thought to contribute to the later development of muscle dysmorphia if it becomes pathologically associated with gaining muscle (Lantz et al., 2001). All nine interview participants referred to a general increase in confidence attributed to training and steroid use. Of the four former users, two were considering using again as a result of this. Participant 3 (former user) commented: "I could never say I'd never go on them again 'cos there's always the attraction of puttin' the weight on again."

The two former users who were not considering reusing had experienced gynecomastia (the formation or swelling of breast tissue), which was what stopped them from reusing. The four former users also mentioned other sources of self-esteem in their lives, such as family and career, with the exception of participant 2, who stated: "I don't feel like I have the time [after training] to focus on my career at the minute ... like relationships I've not really been interested."

Body image distortion/dissatisfaction is the second factor that may contribute to the development of muscle dysmorphia. Each of the four former AAS users who were interviewed showed signs of having a distorted body image and perceived themselves as "smaller" or "less muscular." Participant 1 referred to a conversation he had previously had with a training partner about the condition of his arms after missing training for two weeks: "I said, 'tell you what mate, look at the state of me arms 'cos I've not trained properly, how skinny are they?' an he just started laughin' at me."

The four former steroid users who were interviewed also mentioned their dissatisfaction with their bodies, particularly so for participant 3 , who stated: "I've never ... never really been happy so far . . . no matter how many people praise you an' tell you you look good, you don't feel you look that good in yer head."

However, two of the former users did report being more satisfied with their bodies upon cessation, although they were not completely happy. For example, participant 1 stated that while he was pleased with some elements of his body, he would "never be $100 \%$ happy."

Characteristics of Muscle Dysmorphia. A number of muscle dysmorphia characteristics were visible within the interview group of former users.

Nutrition. Following a strict diet designed to maximize muscle development is a characteristic behavior associated with muscle dysmorphia (Lantz et al., 2001). Three of the four interviewed followed a "typical" bodybuilding diet that was high in protein and low in fat and sugar. These former users (the exception was participant 4) were very strict, with a set menu from which they rarely deviated. They appeared to follow a diet more typically associated with muscle dysmorphic 
behavior, although they were not as strict with calorie counting as the current users. An example of the type of dietary behavior typical of the former users comes from participant 1, who stated, 'I'm just very very controlled so I er I have a protein shake after trainin' in the mornin' an then I have one mid mornin' an then I just have like a normal lunch, and then after I train again I have more protein in like a bar or a shake and then I just have my evenin' meal."

Body Size/Symmetry. Body size/symmetry is thought to be a major source of concern and preoccupation for those with muscle dysmorphic tendencies, according to Lantz et al. (2001). In the interviews with the four former users, body size was a major theme. They all desired a bigger, more muscular physique, which continued on cessation and appeared to be a temptation for two of them to start using again. Participant 3 acknowledged, "Erm I could never say I'd never go on them again cos there's always the attraction of putting the weight on again ... it's the muscular look I think yeah."

Only one of the four former AAS users (participant 4) felt more comfortable with his size on cessation. This was largely due to the negative side effects that he experienced when using steroids, primarily water retention. In contrast, body symmetry was not an issue for any of the four participants interviewed. It was typically size that was more important, typified by the comments of participant 3 when asked what he wanted to achieve: "Er it's the size an the muscular look I think yeah ... there's always the attraction of puttin' the weight on."

Steroid Use. The use of steroids and other pharmacological substances (e.g., diuretics and laxatives) is thought to be more prevalent among those with characteristics of muscle dysmorphia. The use of steroids particularly was important to two of the former users to aid their training and develop their ideal physique. As stated previously, two of the four former users thought that they may use again because of the "benefits" to their physique and confidence. Participant 2 stated, "... they made me happier psychologically ... physique wise I'm better when I'm using."

Participant 3 noted: "When I was on "em me body used to look a lot better. . . . I could never say I'd never go on them again."

The two other former users experienced some negative side effects that had discouraged them from further use, which included gynocomastia and water retention.

Supplement Use. Supplement use is thought to be associated with muscle dysmorphia, according to Lantz et al.'s model (2001). Each of the four former users took supplements and two of the former users suggested using them because of the psychological effect of maintaining muscle size; however, both doubted whether this was a real effect. Participant 3 explained, "I used creatine when I came off gear but a big part of that is probably psychological as well so I thought I wasn't gonna lose weight."

Exercise Dependence. Exercise dependence involves exercising compulsively with a rigid schedule and feeling guilty when missing a training session (Smith, Hale, \& Collins, 1998). The four former AAS users spent more days on average training, with a minimum of 5 days per week. Two of the four former users referred to other priorities in their lives that were more important to them than training; however, the two youngest former users stated that they always put their training above other commitments unless it was something "major." Both of these 
participants both acknowledged that if they were required to miss training it would frustrate and anger them. This was typical of all four of the former users, and was discussed by participant 4: "Missing training? Yeah I'd be pretty gutted to be honest ... it's quite . . quite a hard thing to do for me."

Physique Protection. Physique protection is characterized by attempts to hide a supposed lack of muscle development by wearing baggy clothes and avoiding public exposure of one's physique (Lantz et al., 2001). The former users typically admitted to hiding their physique, exemplified by participant 4: "I actually did cover up a lot more, I mean even in the summer I used to wear thick jumpers an' tracky ... tracksuit bottoms rather than just a t-shirt an' shorts."

Participant 4 also admitted to now training at home rather than at the gym to avoid public exposure of his physique, citing that when training he preferred to "have just one other person there." Three of the four former users exhibited less physique protection behaviors when they were using steroids, as they felt more confident with their physiques.

Negative Consequences: Alienation, Narcissism, and Positive Deviance. Alienation refers to an immersion in the bodybuilding subculture at the expense of work and other social activities (Lantz et al., 2001). The four former AAS users didn't consider themselves to be alienated and did things other than just train. Participant 1 acknowledged his "healthy social life" and participant 3 also acknowledged he had a life away from the gym.

Narcissism is classed as a preoccupation with oneself to the exclusion of others (Lantz et al., 2001). In this case, the preoccupation would focus on one's physique and muscle development. Three of the four former users appeared to demonstrate more preoccupation with their physique "often comparing" themselves to others. However, they rarely did this to the exclusion of others. For example, participant 3 stated, “. . . over the years priorities change . . things come in like work or family commitments . . . it wouldn't take over."

Positive deviance is characterized by "over conformity" to the bodybuilding role and may include training through illness and injury (Lantz et al., 2001). Each of the four former users admitted to training while ill or injured, with the primary concern being to prevent losing their muscular gains. Participant 3 recalled, "I've trained when I've been told not to by doctors an I've trained when I've been really ill but . . . you know you don't want to have too much time off in case yer body starts lookin' worse."

\section{Current Users}

Predisposing Factors: Self-Esteem and Body Distortion/Dissatisfaction. The five current users that were interviewed all referred to an incident in their youth that possibly led to them starting training and later taking steroids to enhance their self-esteem, including bullying and "being fat." Participant 9 indicated, “. . . the reason I first trained was because I was a scrawny little runt an' you know I had been bullied at school."

While the five current users also acknowledged different sources of self-esteem in their lives, they each mentioned an increased confidence that they attributed to steroids and training, and they were not considering stopping and losing these 
"positive" effects. Participant 6 declared, "I would say I'm possibly addicted to the effects of steroids ... erm the psychological effects of well bein' an' the sort of confidence."

Among the interviewed participants, self-esteem appeared to be affected by the improvements to physique from training and particularly AAS use. As this was true of the four former and five current users, both groups appeared to be at a similar risk of developing muscle dysmorphia, as they possessed the predisposing characteristic of self-esteem that was linked to their physiques.

When looking at body image distortion/dissatisfaction, only one of the five current users perceived himself to be "skinny." Participant 8 stated, "I wasn't happy before [steroids] ... I'm not happy with the way I look at the moment, an' I'll never be happy ... I still think I'm skinny."

Three of the five current users expressed some body dissatisfaction, with an increase in size being their main target. Participant 5 exemplified this point as he stated his AAS use goal was to achieve "more size and less body fat," and his training was "all about physique." The other two current users who were interviewed stated that they were "satisfied" with their physiques and used steroids to maintain this look.

Overall, it was the former users in the interview sample who reported more body distortion, although both groups acknowledged being dissatisfied with their bodies to some degree. From the interviews, therefore, it appeared that steroid use reduced body distortion/dissatisfaction, potentially suggesting that former users are at an increased risk of engaging in muscle dysmorphic behaviors. It is important to note, however, that the small sample of interviewees and the self-selected nature of these participants warrant a very conservative approach to the interpretation of these data. It is unknown whether this subgroup of participants differed from the larger sample that completed the MDI, which is quite possible.

Characteristics of Muscle Dysmorphia. A number of muscle dysmorphia characteristics were visible within the interview group of current users.

Nutrition. Three of the five current users were very strict with their diet and all counted calories. The other two current users who were interviewed stated that they had been strict with their diets but this had waned as a result of their changing lifestyles. Participant 8 indicated, "A good number of years ago I did have like er a good ... really good, clean diet an everythin ... it's just tryin' to find time to eat now really between work an the baby." Among those interviewed, steroid use had little effect on the dietary behaviors seen as characteristic of the bodybuilding lifestyle, with diet varying among the five current and four former users.

\section{Body Size/Symmetry.}

The five current users who were interviewed each stated that they desired a bigger, more muscular look and that this appeared was a main motive for using steroids in the first place. Participant 7 explained, "It's just the thrill of getting' more strong ... to get bigger an better an stronger at the gym."

The five current users also acknowledged that they were "bigger" while using steroids, and that maintaining this size was their main motive for continuing to use.

Among the nine interviewed participants, steroid use made little difference to the preoccupation with body size, with both groups demonstrating a preoccupa- 
tion with size alone, suggesting that the experience of this characteristic is similar whether using steroids or not.

Steroid Use. Each of the five current AAS users stated that they were happier and more confident when using steroids. One of the current users (participant 8) claimed that the psychological and physical benefits he received from taking steroids led to the belief that he "couldn't stop." The use of steroids particularly was important to the five current users to aid their training and develop their ideal physique.

The five current users who were interviewed obviously possessed the pharmacological use characteristic of muscle dysmorphia. However, the interviews revealed that two former users were considering restarting steroid use to help them with their gains, which suggests the possible presence of the characteristics of muscle dysmorphia among some of our interviewed former users.

Supplement Use. Each of the five current users used supplements and two of them believed that these supplements benefited their physiques. But, as with the four former users, the current users who were interviewed attributed this to possible psychological gains. Participant 6 acknowledged that he never assessed whether the supplements actually benefitted him, but he thought that they did.

Overall, there was little difference between the two interview groups in their supplement use, with most of the nine participants using them as an aid to training. This suggests that this characteristic was fairly typical among our interviewees.

Exercise Dependence. The five current AAS users who were interviewed reported that they trained three to five times per week, with only one participant training five nights a week. They each acknowledged that they had other priorities in their lives that would come before training, which is not characteristic of the compulsive behavior commonly associated with exercise dependence. Participant 6 stated, "Nowadays it's [training] not that regimented, it's not that important at all ... I'm so busy anyway that it's not so important to me." Further, participant 8 asserted, "I mean I have to miss it a lot of times . . . lots of times the baby's not well or there's . . . there's nobody to look after the baby." Despite these "other priorities," the five current users stated that they were annoyed if they did miss a training session for something they classed as "unimportant."

Overall, there was little difference in the levels of exercise dependence among this small sample of interviewees. Both the five current and four former users expressed an annoyance at missing training. However, the little difference that there was indicates that the four former users exercised more frequently, with two admitting to prioritizing training over other commitments.

Physique Protection. The five current AAS users who were interviewed reported less "physique protection" behaviors than the four former users, with most being comfortable to show their physique. This is typified by participant 7, who stated, "In the gym, no, I don't have a problem no . . . I've no desire to particularly show meself off er to other people . . but if they want to have a look then fine!"

One of the current users did exhibit physique protection behaviors, particularly when he had missed a training session. Participant 8 noted, "I mean after the baby was born I'd not trained properly for well it was just three or four times a month ... I went back to the gym an I looked at meself an thought [2 secs] no . . I just 
had like a normal t-shirt on. . . I just felt bad about meself." He also mentioned that he had, on a few occasions "made a poor excuse for not goin' on a night out" if he put a shirt on that was too baggy. Within our sample of five current AAS users, the participants reported fewer physique protection behaviors than the four former users, possibly suggesting that cessation may be associated with this element of muscle dysmorphia.

Negative Consequences: Alienation, Narcissism, and Positive Deviance. The five current AAS users who were interviewed all acknowledged a healthy social life outside of the gym. Participant 5 indicated, "I have a good social life outside of the gym too. I mean I'd say more of me spare time is revolved around the gym than the pub was if that makes sense, but I do have friends outside an' I still do things outside."

It would appear that steroid use had little effect on the experience of alienation in the present context, with the five current and four former users displaying few signs of alienation from their lives "outside" of the gym environment. In terms of narcissism, the five current AAS users were not overly preoccupied with themselves, and although they were aware of physique changes, this did not appear to come at the expense of others. Participant 5 stated, "I just want to improve meself . . . but generally if you've got a bit of common sense you can fit things in around it, I mean real life does have a place too doesn't it."

Overall the experience of narcissism did not appear to differ between the groups, with the four former users mentioning their physique only slightly more often. Finally, when looking at positive deviance, three of the five current AAS users had trained while ill or injured, although only participant 8 had trained with a serious injury. Participant 8 noted, "I tore me rotator cuff... badly . . . so I hammered ibuprofen all day an' all night an I was back on the Friday doin' shoulders again." The two other current users had only trained with minor injuries or illness and stated that they believed it was important to rest injuries.

Overall, steroid cessation among our interviewees appeared to be linked with positive deviance to the bodybuilding role, shown by more of a willingness to train when ill or injured. Although the five current users exhibited some similar behaviors, they appeared to be prepared to miss training or rest the injured body part, according to their statements.

\section{Discussion}

The main aim of the current study was to compare the characteristics of muscle dysmorphia among current and former steroid users, using Lantz et al.'s (2001) conceptual model of muscle dysmorphia. A mixed-methods approach was used that combined the MDI with an in depth interview

In relation to the results, the lack of difference between current and former users on the MDI scale was unexpected. Cafri et al. (2005) suggested that a preoccupation with muscularity often culminates in the abuse of steroids. While this could have been true of the steroid users in the present sample in terms of why they started using steroids, we might expect that the experience of muscle dysmorphia characteristics would decline in former users if they no longer feel the need to use steroids. However, this was not the case here as there was no significant difference 
between the groups and, in fact, the former users had higher mean scores on all but one of the MDI subscales (Table 2). This also provided support for reports of the persistence of muscle dysmorphia on cessation (Cole et al., 2003), given that the mean scores on most of the MDI subscales were moderate to high for both groups and just as high for the former users as the current users. Therefore, though much attention has been paid to muscle dysmorphia among steroid users, we argue that more attention should be paid to this phenomenon among former users. The intuitive hypothesis that former users should be lower in muscle dysmorphia as they no longer need to use the drugs to feel positive about their bodies, was not supported by the data. This should be of concern to health professionals, as presumably the continued presence of muscle dysmorphia may make steroid use recidivism more likely. While longitudinal research is needed to determine whether this is the case, the present findings suggest the need for psychological support to be given to those ceasing the use of such drugs, as these individuals may still struggle with characteristics of muscle dysmorphia.

Another important issue arising from these findings is that, given that the MDI scores of the steroid users were not significantly lower than those who had ceased use, steroid use may not be a very successful way of coping with muscle dysmorphia. If it were, then given that much of the muscle gained from steroid use atrophies upon ceasing use, we would expect that muscle dysmorphia symptoms may increase at that time. Of course, the use of such drugs for nonmedical purposes is already contraindicated due to possible physical health risks, but interestingly, these data suggest that they may not be helpful in reducing feelings of muscle dysmorphia. For a more thorough examination of this issue, future studies should compare MDI scores before and after the commencement of steroid use.

Our quantitative data have produced some interesting findings. Although the MDI is a well-validated research tool, however, such survey methods may fail to capture some of the subtleties of the perceptions and experiences of participants. Therefore, the second part of our study focused on the interview data from the subsample of nine participants. It is important to emphasize the limitations of this approach, however. Specifically, the small and self-selected nature of our interview sample limits the degree to which these findings can be generalized to this population as a whole. Nevertheless, our interview data produced some intriguing findings that we hope will serve as a stimulus for further research investigation.

Table 2 Mean MDI Scores for Current $(n=5)$ and Former $(n=4)$ AAS Users

\begin{tabular}{llll}
\hline & $\begin{array}{l}\text { Current AAS } \\
\text { Users }\end{array}$ & $\begin{array}{l}\text { Former AAS } \\
\text { Users }\end{array}$ & $\begin{array}{l}\text { Maximum } \\
\text { Score }\end{array}$ \\
\hline Nutrition & 21.2 & 21.9 & 30 \\
Supplement use & 16.5 & 17.1 & 24 \\
Pharmacological abuse & 7.6 & 6.2 & 18 \\
Exercise dependence & 17.8 & 19.2 & 24 \\
Physique protection & 13.9 & 14.2 & 36 \\
Body size/symmetry & 20.5 & 21.7 & 30 \\
\hline
\end{tabular}


The first thing to note is that the interview portion of the study also showed little difference between the groups in the experience of some muscle dysmorphia characteristics. Nutrition and supplement use were similar among the participants in both interview groups, as was the body size/symmetry characteristic. Increasing body size appeared to be a major source of preoccupation, adding preliminary support to prior literature, suggesting that this is a major source of concern for recreational bodybuilders (Lantz et al., 2001). Past literature also reported that gaining size and muscle was a key motive for AAS use (Wright et al., 2000), but interestingly, in the present context, concern about body size persisted on cessation for the four former users who were interviewed. A possible reason for this comes from research, suggesting a pressure from within the bodybuilding culture (Collier, Smith, \& Liston, 2006), which would remain for former users here as they were still involved in this culture. Of course, due to the investigational nature of this study, these results only suggest tentative hypotheses that need to be further investigated. Therefore, future longitudinal research could examine recreational bodybuilders before they have considered using steroids to determine whether pressure from within the bodybuilding subculture contributes to later muscle dysmorphia.

In contrast, an overall lack of concern with body symmetry was preliminarily supported from the interview content. This would perhaps be more of an issue for competitive rather than recreational bodybuilders, as this is a main criterion of the judging (http://www.nabba.com/rules, 2008). This is an interesting empirical question that requires investigation.

While there were a number of similarities between the five current and four former AAS users, the interviews also revealed some interesting differences. Most of those interviewed did not provide supporting evidence for exercise dependence behaviors, conceding that they would miss training if something else arose (e.g., work or family event). However, the most extreme exercise dependent behaviors were displayed by two former users who acknowledged that they would put training before everything unless it was a "major" emergency, and such stringent exercise behaviors could possibly be attributed to the fact that they are no longer taking steroids and so feel the need to work harder to maintain their size. This explanation is somewhat speculative and requires further investigation. Indeed, the psychological effects of steroids, such as increased motivation, can enable participation in higher intensity training, which would be likely to decline on cessation (Friedl, 2000).

When looking at physique protection, the four former AAS users again provided preliminary support for this element of the model. Most of the five current users who were interviewed stated that they were comfortable with their physiques, with the exception of participant 8 who referred to himself as "skinny" and also covered his physique; however, physique protection behaviors were more prevalent in the interviews of the four former users. This is consistent with Cole et al.'s findings, in that this particular characteristic of muscle dysmorphia did remain on cessation. It may also support the suggestion that using steroids is a consequence of a concern with developing muscularity and that this concern may be reignited on cessation (Cafri et al., 2005; Davidson, 2008), further reinforced by the former users' comments that they had only started to engage in physique protection behaviors on cessation. Of course, as the individuals were not questioned before their steroid use had started, longitudinal research is required to test this hypothesis. 
Examining the pharmacological abuse characteristic, most of the five current users stated that they were happier with their physique and confident, offering preliminary support for findings that the main motives for steroid use are physiquebased (Cohen et al., 2007; Smith et al., 2009) with further preliminary support from two of the four former users who were considering reusing steroids because they missed the physical gains that they had attained when using. This confidence that was attributed to AAS use was also noted when examining the predisposing factors of muscle dysmorphia. Self-esteem is thought to become associated with muscle building activities, such as increased training and dietary behaviors, and for muscle dysmorphia to occur when one is thought to become dependent on the association between heightened self-esteem and such activities (Lantz et al., 2001). In the current study, self-esteem was linked to training in both interview groups, but the current users' data preliminarily supported the idea that self-esteem from steroids impacted their physical appearance and general life. The four former users also acknowledged that they felt better about themselves when using steroids. While they all acknowledged having other sources of self-esteem such as family and work, they were all still part of the bodybuilding culture and two of the four former users were considering reusing steroids. This in part contrasts with findings that steroid cessation is motivated by users gaining other sources of self-esteem (Olrich \& Ewing, 1999; Olrich \& Vassallo, 2006). While an open empirical question, if it is found to be supported by future research, this could potentially have implications when looking to support people who are considering or have stopped using steroids, in that the psychological effects of cessation may not just be about losing size, but may also be concerned with feeling less confident and positive in life overall. The interview data also provided preliminary support for the idea that former users may be as likely to experience muscle dysmorphia as current users, as they would still associate their self-esteem with the physique that they had acquired while using steroids; however, these findings require further investigation with a larger sample size.

A similar pattern was reported in the second predisposing factor of body distortion/dissatisfaction. Body distortion appeared to be more of a concern for the four former AAS users. Both groups' data suggested a degree of body dissatisfaction and again was more frequently mentioned among the former users. As with self-esteem, the use of steroids appeared to have improved the body image of the present sample, although again it is probable that high levels of body distortion/dissatisfaction led to steroid use. This was implied by the current users, who mentioned being "fat" or "scrawny" before using steroids. The discussion of body distortion/ dissatisfaction among the former users interviewed also lends preliminary support to the suggestion of the persistence of muscle dysmorphia in former users (Cole et al., 2003) and suggests that cessation may lead to an increase body dissatisfaction due to an initial loss in size (Davidson, 2008).

The final elements of Lantz et al.'s (2001) model that were discussed in the interviews were the negative consequences of alienation, narcissism, and positive deviance. Both groups provided little supportive evidence of alienation, and this was perhaps a consequence of the sample of participants used. If descriptions of the all-consuming, obsessive bodybuilding subculture were true of the current sample, it is unlikely that they would have signed up to participate in the study in the first 
instance (Fussell, 1991; Klein, 1993), as they would have been too preoccupied with training and their lifestyle.

Similarly, narcissistic tendencies were largely absent from the two groups' data. While each of the nine interviewees were aware of their physiques and noted changes to them, the majority did not mention being overly preoccupied to the extent where they began to exclude others. The four former users did, however, appear to discuss their body more often and monitored their body more closely. This could be attributed to the fact that they have had attention drawn to their physique as a result of the initial loss in mass that is a normal consequence of steroid cessation (Davidson, 2008).

The final negative consequence, positive deviance, includes behaviors such as training through illness or injury. The four former AAS users appeared to exhibit greater evidence of positive deviance than current users. It may be that these participants trained through illness or injury because they did not want to lose any more muscle mass, and indeed this was a factor given as a justification for doing so by the majority of former users.

A further point of interest from the interview data, more specific to Lantz et al.'s (2001) conceptual model, is the pattern of the characteristics experienced. As can be seen from a summary of the interviews in Table 3, all participants experienced the various characteristics differently and the pattern was not consistent. What is clearly lacking is a diagnostic tool to determine how extreme such characteristics are before anyone can be classed as being "muscle dysmorphic." It is also important to consider that factors identified in this study as being important within this subculture, such as social and life events, are experienced on an individual level. Future research could perhaps focus more on these differences and whether people having such aspects in common have similar patterns of muscle dysmorphia; rather

\section{Table 3 Presence or Absence of Characteristics From Lantz et al.'s (2001) Conceptual Model Dysmorphia in Current and Former AAS Users}

\begin{tabular}{lccccccccc}
\hline & $\begin{array}{c}\text { Part } \\
\mathbf{1}\end{array}$ & $\begin{array}{c}\text { Part } \\
\mathbf{2}\end{array}$ & $\begin{array}{c}\text { Part } \\
\mathbf{3}\end{array}$ & $\begin{array}{c}\text { Part } \\
\mathbf{4}\end{array}$ & $\begin{array}{c}\text { Part } \\
\mathbf{5}\end{array}$ & $\begin{array}{c}\text { Part } \\
\mathbf{6}\end{array}$ & $\begin{array}{c}\text { Part } \\
\mathbf{7}\end{array}$ & $\begin{array}{c}\text { Part } \\
\mathbf{8}\end{array}$ & $\begin{array}{c}\text { Part } \\
\mathbf{9}\end{array}$ \\
\hline $\begin{array}{l}\text { Self-esteem related to } \\
\text { bodybuilding }\end{array}$ & $\mathrm{Y}$ & $\mathrm{Y}$ & $\mathrm{Y}$ & $\mathrm{Y}$ & $\mathrm{Y}$ & $\mathrm{Y}$ & $\mathrm{Y}$ & $\mathrm{Y}$ & $\mathrm{Y}$ \\
$\begin{array}{l}\text { Body distortion/ } \\
\text { dissatisfaction }\end{array}$ & & & & & & & & & \\
Nutrition & $\mathrm{Y}$ & $\mathrm{Y}$ & $\mathrm{Y}$ & $\mathrm{Y}$ & $\mathrm{Y}$ & $\mathrm{N}$ & $\mathrm{N}$ & $\mathrm{Y}$ & $\mathrm{Y}$ \\
Supplement use & $\mathrm{Y}$ & $\mathrm{Y}$ & $\mathrm{Y}$ & $\mathrm{N}$ & $\mathrm{N}$ & $\mathrm{Y}$ & $\mathrm{Y}$ & $\mathrm{N}$ & $\mathrm{Y}$ \\
Pharmacological abuse & $\mathrm{Y}$ & $\mathrm{Y}$ & $\mathrm{Y}$ & $\mathrm{Y}$ & $\mathrm{Y}$ & $\mathrm{Y}$ & $\mathrm{Y}$ & $\mathrm{Y}$ & $\mathrm{Y}$ \\
Exercise dependence & $\mathrm{Y}$ & $\mathrm{Y}$ & $\mathrm{N}$ & $\mathrm{Y}$ & $\mathrm{Y}$ & $\mathrm{Y}$ & $\mathrm{Y}$ & $\mathrm{Y}$ \\
Physique protection & $\mathrm{Y}$ & $\mathrm{Y}$ & $\mathrm{Y}$ & $\mathrm{Y}$ & $\mathrm{N}$ & $\mathrm{N}$ & $\mathrm{N}$ & $\mathrm{N}$ & $\mathrm{N}$ \\
Body size/symmetry & $\mathrm{Y}$ & $\mathrm{Y}$ & $\mathrm{Y}$ & $\mathrm{Y}$ & $\mathrm{Y}$ & $\mathrm{Y}$ & $\mathrm{Y}$ & $\mathrm{Y}$ & $\mathrm{N}$ \\
Alienation & $\mathrm{N}$ & $\mathrm{N}$ & $\mathrm{N}$ & $\mathrm{N}$ & $\mathrm{N}$ & $\mathrm{N}$ & $\mathrm{N}$ & $\mathrm{N}$ & $\mathrm{N}$ \\
Narcissism & $\mathrm{N}$ & $\mathrm{Y}$ & $\mathrm{N}$ & $\mathrm{N}$ & $\mathrm{N}$ & $\mathrm{N}$ & $\mathrm{N}$ & $\mathrm{N}$ & $\mathrm{N}$ \\
Positive deviance & $\mathrm{Y}$ & $\mathrm{Y}$ & $\mathrm{Y}$ & $\mathrm{Y}$ & $\mathrm{Y}$ & $\mathrm{Y}$ & $\mathrm{N}$ & $\mathrm{Y}$ & $\mathrm{N}$ \\
\hline
\end{tabular}

Note. Participants 1-4 were former users, Participants 5-9 were current users. 
than grouping people according to their steroid use, researchers could perhaps group them according to similarities in more personal life experiences. A larger, more tightly controlled study is needed to examine these issues and test the various hypotheses that we tentatively offer on the basis of our interview data.

\section{Limitations}

There are some limitations of the current study. Chief among these is the aforementioned small sample size in the interview portion of the study and the fact that the interviewees were self-selected among the larger group of participants. It is quite possible that these individuals differed (in terms of personality traits, AAS use history, and/or experiences) from the questionnaire respondents, who did not consent to be interviewed. Therefore, we cannot at this time generalize our data and instead suggest that these preliminary findings await replication and further empirical investigation.

In addition, it is possible that the current users who were interviewed downplayed their behaviors related to steroid use, and it was clear that they were defensive when questioned. This could possibly be due to feeling "victimized" because of the negative media reports of steroid use, which would support findings by Olrich and Vassallo (2006) that users themselves have more positive experiences of AAS use than the media portray. If true, this could have implications in terms of devising methods to support cessation, as demonizing steroid use could potentially alienate the users further. This suggestion should be seen in the light of the limitations and requires empirical investigation.

A common theme to emerge from the interviews was the amount of research and advice gained before starting to use steroids. The participants also believed that they took precautions in terms of regular health checks, using needle exchanges and cycling their steroid use. The potential bias in this sample must be acknowledged in that participants were largely recruited from advice-giving internet forums, and it would perhaps add external validity if they were from more "hardcore" bodybuilding gyms (Lenehan et al., 1996). It is also worth considering that those with more extreme symptoms of muscle dysmorphia may be unlikely to participate in such research, making it difficult to get a true indication of its prevalence.

Also, interview data are problematic in that they have the potential to be subject to interpretive bias (Robson, 2003). Precautions were taken to ensure that the qualitative data were as reliable as possible, however, using a mixed methods approach to "double check" findings (Miles \& Huberman, 1994) and also combining the separate analyses of the interviews by two authors. While the themes were largely consistent, one author argued that there should have been more probing on issues related to risk taking and avoidance behaviors as motives and consequences of AAS use, which is recommended as an area for future research.

\section{Conclusions}

The combined data appeared to suggest that current and former AAS users experienced muscle dysmorphia similarly. The interview data preliminarily suggest that muscle dysmorphia can persist upon steroid cessation (Cole et al., 2003) and if replicated and advanced in future research, may suggest implications in terms 
of the coping strategies given to those wishing to stop such use. Due to the nature of interview data (Robson, 2003) and the study's limitations, however, caution must be taken when attempting to generalize the results. Participants' experiences relating to the elements of Lantz et al.'s (2001) model were not consistent. It is also difficult to determine the severity of the characteristics experienced without a diagnostic tool. Such a tool would enable the prevalence of muscle dysmorphia to be more effectively investigated and would raise awareness of this condition among bodybuilders, other athletes, and importantly, among health professionals. The qualitative portion of the current study suggests the possible presence of pathological behaviors and attitudes related to the development of a muscular physique, suggesting that the need for a means of diagnosing this condition should be a priority in future research. Further investigation of individual factors such as social and lifestyle factors, as well as personality factors including risk taking and avoidance behaviors, may help contribute to such a list of diagnostic criteria.

\section{References}

Armstrong, D., Gosling, G., Weinman, J., \& Marteau, T. (1997). The place of inter-rater reliability in qualitative research: An empirical study. Sociology, 31, 597-606.

Brannen, J. (2005). Mixing methods: The entry of qualitative and quantitative approaches into the research process. International Journal of Social Research Methodology, 8, 173-184.

Cafri, G., Thompson, J.K., Ricciardelli, L., McCabe, M., Smolak, L., \& Yesalis, C. (2005). Pursuit of the muscular ideal: Physical and psychological consequences and putative risk factors. Clinical Psychology Review, 25, 215-239.

Cohen, J., Collins, R., Darkes, J., \& Gwartney, D. (2007). A league of their own: Demographics, motivations and patterns of use of 1,955 male adult non-medical anabolic steroid users in the United States. Journal of the International Society of Sports Nutrition, 4, 1-14.

Cole, J.C., Smith, R., Halford, J.C.G., \& Wagstaff, G.F. (2003). A preliminary investigation into the relationship between anabolic-androgenic steroid use and the symptoms of reverse anorexia in both current and ex-users. Psychopharmacology, 166, 424-429.

Collier, K., Smith, D., \& Liston, K. (2006, September). Motivations for anabolic androgenic steroid use amongst recreational bodybuilders: A case study. Paper presented the annual meeting of the Association for the Advancement of Applied Sport Psychology, Miami, FL.

Davidson, C. (2008, May 18). From Mr. Average to Superman. The Observer Magazine, pp. 36-45.

Friedl, K.E. (2000). Effect of anabolic steroid use on body composition and physical performance. In C.E. Yesalis (Ed.), Anabolic steroids in sport and exercise (2nd ed., pp. 139-174). Champaign, IL: Human Kinetics.

Fussell, S.W. (1991). Muscle: Confessions of an unlikely bodybuilder. New York: Poseidon.

Garner, D.M., Olmstead, M.P., \& Polivy, J. (1983). Development and validation of a multidimensional eating disorder inventory for anorexia nervosa and bulimia. The International Journal of Eating Disorders, 2, 15-34.

Grogan, S., Shepherd, S., Evans, R., Wright, S., \& Hunter, G. (2006). Experiences of anabolic steroid use: In-depth interviews with men and women body builders. Journal of Health Psychology, 11, 845-856.

Harden, A., \& Thomas, J. (2005). Methodological issues in combining diverse study types in systematic reviews. International Journal of Social Research Methodology, 8, 257-271.

Klein, A. (1993). Little big men: Bodybuilding subculture and gender construction. $\mathrm{PhD}$ Dissertation, State University of New York, Albany. 
Lantz, C.D., Rhea, D.J., \& Cornelius, A.E. (2002). Muscle dysmorphia in elite-level lifters and bodybuilders: A test of differences within a conceptual model. Journal of Strength and Conditioning Research, 16, 649-655.

Lantz, C.D., Rhea, D.J., \& Mayhew, J.L. (2001). The drive for size: A psycho-behavioral model of muscle dysmorphia. International Sports Journal, 5, 71-86.

Lenehan, P., Bellis, M., \& McVeigh, J. (1996). Anabolic steroid use in the North West of England - A summary. Liverpool: Drugs and Sport Information Service.

Miles, M.B., \& Huberman, A.M. (1994). Qualitative data analysis: An expanded sourcebook. Thousand Oaks, CA: Sage.

Olivardia, R., Pope, H.G., \& Hudson, J.I. (2000). Muscle dysmorphia in male weightlifters: A case-control study. The American Journal of Psychiatry, 157, 1291-1296.

Olrich, T.W., \& Ewing, M.E. (1999). Life on steroids: Bodybuilders describe their perceptions of the anabolic-androgenic steroid use period. The Sport Psychologist, 13, 299-312.

Olrich, T.W., \& Vassallo, M. (2006). Psychological dependency to anabolic-androgenic steroids: Exploring the role of social mediation. New England Law Review, 40, 735-746.

Pope, H.G., Gruber, A., Choi, P.Y., Olivardia, R., \& Phillips, K.A. (1997). Muscle dysmorphia: An under-recognised form of body dysmorphic disorder. Psychosomatics, $38,548-557$.

Rhea, D.J., Lantz, C.D., \& Cornelius, A.E. (2004). Development of the Muscle Dysmorphia Inventory (MDI). Journal of Sports, Medicine, and Physical Fitness, 44, 428-435.

Robson, C. (2003). Real world research (2nd ed.). Oxford, UK: Blackwell Publishing.

Silverman, D. (2004). Qualitative research: Theory, method and practice. London: Sage.

Smith, D., Hale, B.D., \& Collins, D. (1998). Measurement of exercise dependence in bodybuilders. Journal of Sports, Medicine, and Physical Fitness, 38, 66-74.

Smith, D., Hale, B.D., Rhea, D., Olrich, T., \& Collier, K. (2009). Big, buff and dependent: Exercise dependence, muscle dysmorphia and anabolic steroid use in bodybuilders. In L.J. Katlin (Ed.), Men and addictions: New Research (pp. 1-36). New York: Nova Science.

Wright, S., Grogan, S., \& Hunter, G. (2000). Motivations for anabolic steroid use among body builders. Journal of Health Psychology, 5, 566-572. 